\title{
Predictive modeling of discharge of flow in compound open channel using radial basis neural network
}

\author{
Abbas Parsaie $^{1} \cdot$ Shadi Najafian $^{2} \cdot$ Zahra Shamsi $^{3}$
}

Received: 23 July 2016/ Accepted: 26 July 2016/Published online: 6 August 2016

(C) Springer International Publishing Switzerland 2016

\begin{abstract}
Predicting the flow discharge in open channel is the main parameters in the flood management. The concept of the compound open channel is the accurate approach for modeling the natural streams. Several ways as analytical approaches and artificial intelligence methods have been proposed for predicting the discharge in rivers in term of compound open channel concepts. In this paper the single channel method (SCM), coherence method (COHM), and divided channel method (DCM) as common analytical approaches were used to predict the discharge in the compound open channel and in follow to achieve more accuracy in flow discharge prediction the radian basis neural network (RBF) was developed. The performance of $\mathrm{RBF}$ was compared with other types of transfer function governed on neurons of neural network. The results showed that the DCM with horizontal separated boundary among the subsections with correlation of determination $\left(\mathrm{R}^{2}=0.76\right)$ is accurate through the analytical approaches. Assessing the results of the MLP model showed that this model with $\left(\mathrm{R}^{2}=0.95\right)$ is a bit more accurate than the $\mathrm{RBF}\left(\mathrm{R}^{2}=0.85\right)$ and analytical approaches.
\end{abstract}

Abbas Parsaie

Abbas_Parsaie@yahoo.com

Shadi Najafian

sh_najafyan@yahoo.com

Zahra Shamsi

azm.shams@gmail.com

1 Water Engineering Department, Lorestan University, Khorramabad, Iran

2 Department of Water Engineering, Lorestan University, Khorramabad, Iran

3 Department of Water and Soil Conservation, Ministry of Agriculture Jihad, Kerman, Iran
Keywords Discharge prediction - Flood management . River engineering · Artificial neural network

\section{Introduction}

Flood forecasting in natural streams play an important role in the water harvesting projects (Chow et al. 2013). Several ways as empirical and numerical approaches has been proposed to predict the discharge in the rivers (Mohanty and Khatua 2014). In this regard the concept of the compound open channel is accurate approach for calculating the discharge of flow in the rivers (Wang et al. 2014; Qishlaqi et al. 2016). The compound open channel as seems in Fig. 1 divided the river cross section in two parts as main channel and floodplain(s).

The compound open channel concept characterized the roughness between the main channel and floodplain(s) (Te Chow, 2009). The main point of advantage the compound open channel concept is related to the defining hydraulic properties the each part of the cross section individually (Al-Khatib et al. 2012; Khatua et al. 2012). Several analytical and numerical methods have been proposed for predicting the flow discharge in the compound open channel (Dehdar-behbahani and Parsaie 2016; Parsaie et al. 2015a; Othman and Valentine 2006; Naot et al. 1993). In this regard using the Single-Channel Method (SCM) was used by Seckin (2004), the Divided-Channel Method was used by Atabay and Knight (2006) and the Coherence Method was used by Ackers (1993) as analytical approaches can be mentioned. The Artificial intelligent techniques (AI) recently widely used in the water engineering studies especially in the flood forecasting in the rivers (Parsaie et al. 2016). Recently researchers used the number of the AI models for prediction flow discharge in the rivers. In 


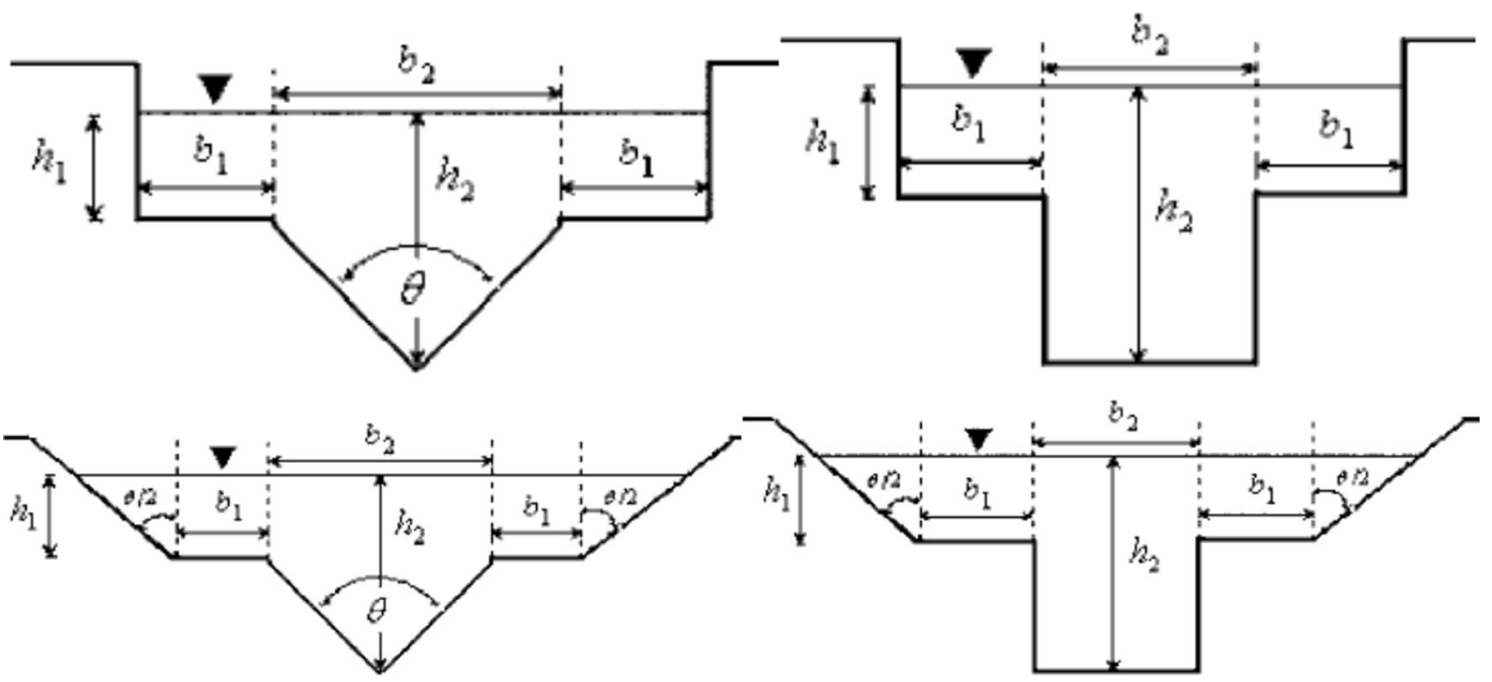

Fig. 1 Compound open channel cross sections

this regard using the Artificial Neural Network, M 5 tree model, Gene Expression Method, SVM (Parsaie et al. 2015c), and Group Method of Data Handling can be mentioned based on the reports the accuracy of the AI models is much more than the empirical approaches(Zahiri and Azamathulla 2014; Wang et al. 2014; Al-Khatib et al. 2013; Kozioł 2013; Yonesi et al. 2013; Azamathulla and Zahiri 2012; Khatua et al. 2012; Sahu et al. 2011; Unal et al. 2010; Knight et al. 1984; Parsaie et al. 2015b; Parsaie and Haghiabi, 2016). In this paper using the radial basis function neural network due to simple its structure for prediction of flow in compound open channel is considered.

\section{Materials and methods}

Flow discharge in compound open channels is proportional of the hydraulic and geometrics characteristics. Equation (1) presents the most important hydraulic and geometric which are affective on the flow discharge in the compound open channel.

$Q_{c m p}=f\left(f_{f p}, f_{m c}, A_{m c}, A_{f p}, R_{f t}, R_{m c}, S, h,(H-h)\right)$,

where $f_{f p}$ is flood plain roughness, $f_{\mathrm{mc}}$ is main channel roughness, $A_{m c}$ is main channel area, $A_{f p}$ is floodplain areas, $R_{f t}$ is the hydraulic radios of the flood plains, $R_{m c}$ is the main channel hydraulic radios, $\mathrm{S}$ is the longitudinal slope, $\mathrm{h}$ is the main channel depth and $H-h$ is the flow depth in the floodplains. Based on Eq. (1) researchers try to propose the most popular dimensionless parameters which are given in the Eq. (2) (Sahu et al. 2011; Unal et al. 2010; Seckin et al. 2009). Developing the analytical approaches and AI models is based on these parameters which were given in the Eq. (2).

$Q_{m}=f\left(f_{r}, A_{r}, R_{r}, S, H_{r}\right)$,

where $\mathrm{S}$ is the longitudinal slope of the compound open channel, $n_{r}$ is defined as $f_{m d} / f_{f p}, A_{r}$ is defined as $A_{m d} / A_{f p}, R_{r}$ is defined as $R_{m c} / R_{f p}, D_{r}$ is defined $(H-h) / H$, and $Q_{m}$ is the measured discharge (Rezaei and Knight 2009; Padhi and Patra 2014). Developing the AI models is based on the data set so for predicting the flow discharge in compound open channel, 396 dataset related to the Eq. (2) was collected from the articles which published on the reliable journals. Some of the most famous of the articles are given as Table (1). All the stages of development of MLP and RBF models were programed in the environment of Matlab software. The histogram of collected dataset are given in Fig. 2. The dataset were collected from the published article including Knight et al. (1984), Wormleaton and Hadjipanos (1985), Wormleaton and Merrett (1990) (UK Flood Channel Facility), Tang et al. (1999), Seckin (2004), Lenton and Muller (2012), Atabay and Knight (2006), Atabay and Knight (2006), Khatua et al. (2012), Mohanty and Khatua (2014).

Table 1 Summary of collected data range related to discharge in the compound channel

\begin{tabular}{lllllll}
\hline Range & $n_{r}$ & $A_{r}$ & $R_{r}$ & $\mathrm{~S}$ & $D_{r}$ & $Q_{m}$ \\
\hline Min & 1.000 & 0.047 & 0.020 & 0.000 & 0.041 & 0.005 \\
Max & 6.408 & 2.909 & 0.195 & 0.002 & 0.773 & 1.114 \\
AVG & 1.306 & 0.651 & 0.066 & 0.001 & 0.303 & 0.144 \\
STDEV & 0.999 & 0.424 & 0.038 & 0.001 & 0.167 & 0.218 \\
\hline
\end{tabular}




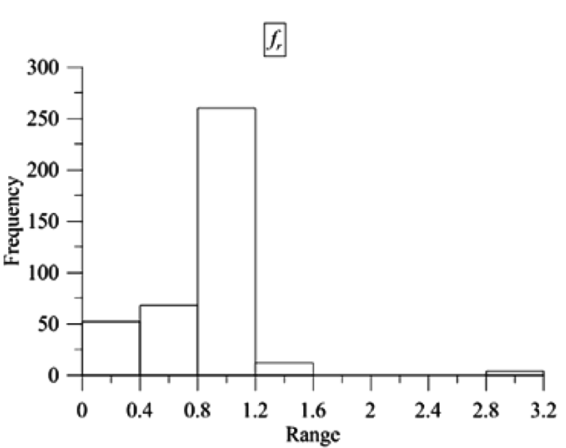

$S$

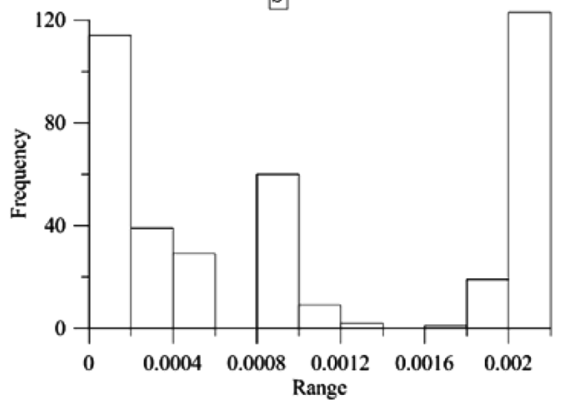

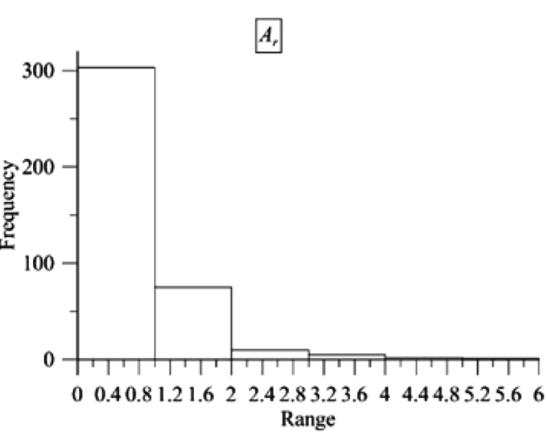

H,

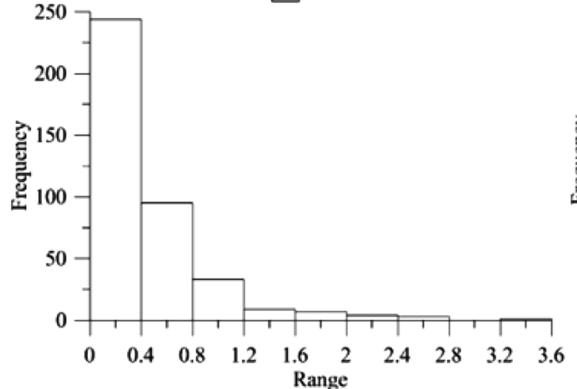

$R_{r}$

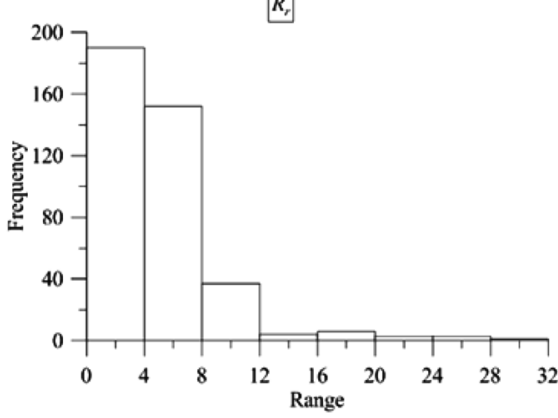

$Q_{m}$

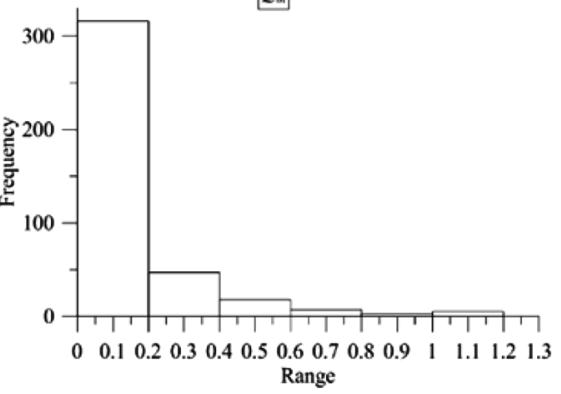

Fig. 2 The histogram of collected data involved discharge of flow in compound open channel

Fig. 3 A three-layer ANN architecture

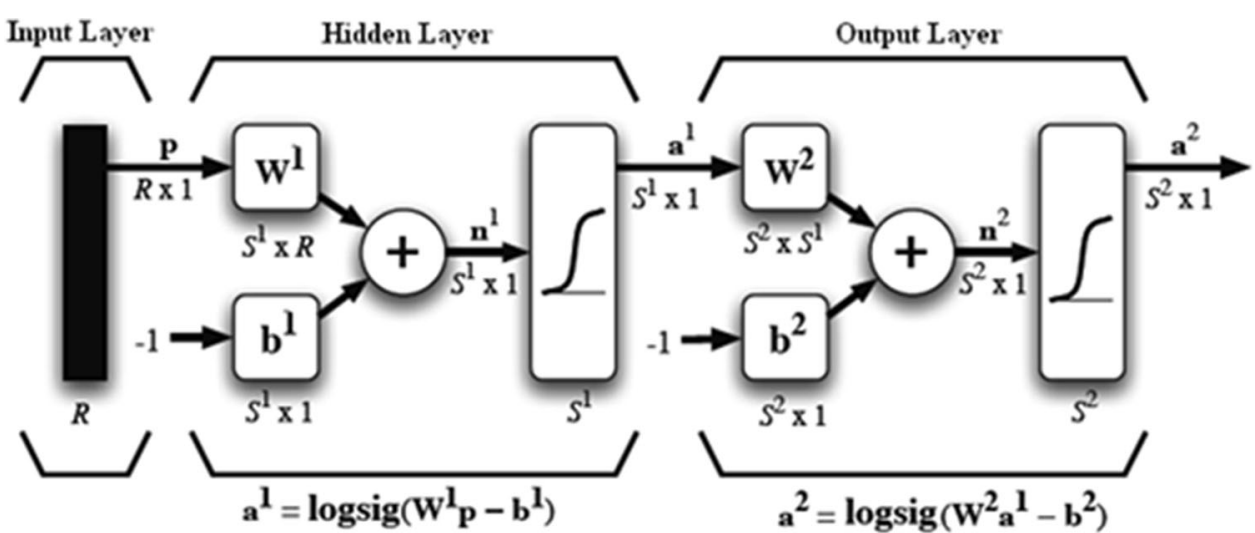

$n_{e}=\frac{\left[\sum_{i=1}^{N}\left(P_{i} n_{i}^{3 / 2}\right)\right]^{\frac{2}{3}}}{P^{\frac{2}{3}}}$

Researchers have tried to modify the classical analytical approaches for calculation flow discharge in compound open channels. In this regard the Single channel method (SCM), The Divided Channel method (DCM) and the coherence method (COHM) can be stated. In the SCM method, the compound open channel cross section has been considered as a unique cross section and there is not any difference between the normal and compound channel and manning roughness coefficient is calculated by Horton and Einstein formula so the total flow discharge is calculated by Eq. (3a, 3b).

$Q=\frac{1}{n_{e}} A R^{\frac{2}{3}} S^{\frac{1}{2}}$
The Divided Channel method (DCM) is divided the compound channel to number sub sections. In this method the compound channel section is divided to the main channel and floodplains and total discharge is calculated by adding the sub sections discharge. The discharge in subsections calculates by Eq. (4). The separation line between the main channel and floodplains may be considered as vertical, diagonal or horizontal. The divided channel method with horizontal division lines which are included within the calculation of wetted perimeter [DCM $(h-i)]$, the divided channel method with vertical division lines which are included within the calculation of wetted perimeter 
[DCM ( $\mathrm{v}-\mathrm{i})]$, and the divided channel method with bisectional division lines which are included within the calculation of wetted perimeter [DCM (b-i)] (Atabay and

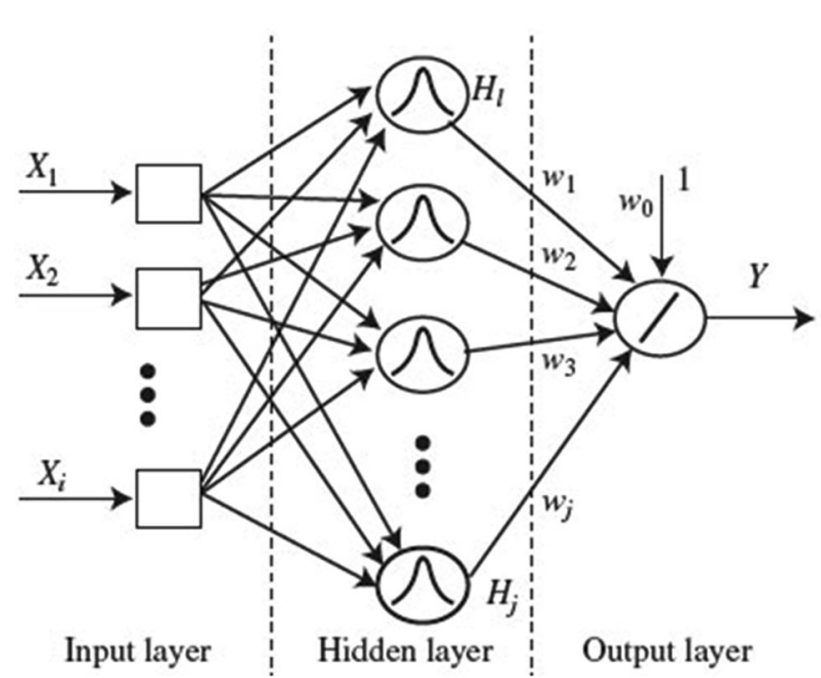

Fig. 4 A RBF model structure (Parsaie and Haghiabi 2015c)
Knight 2006). Some commercial software such as HECRAS, Mike 11 and ISIS has been developed based on the DCM (Parsaie 2016; Azamathulla et al. 2016; Parsaie and Haghiabi 2014; Moasheri et al. 2013).

$Q_{t}=\left(\sum_{i=1}^{N} \frac{A_{i} R_{i}^{\frac{2}{3}}}{n_{i}}\right) S_{0}^{\frac{1}{2}}$

\section{Multilayer Perceptron (MLP) neural network}

ANN is a nonlinear mathematical model that is able to simulate arbitrarily complex nonlinear processes that relate the inputs and outputs of any system. In many complex mathematical problems that lead to solve complex nonlinear equations, Multilayer Perceptron networks are common types of ANN that are widely used by the researches. To use MLP model, definition of appropriate functions, weights and bias should be considered. Due to the nature of the problem, different activity functions in neurons can be used. An ANN maybe has one or more hidden layers. Figure 3 demonstrates a three-layer neural
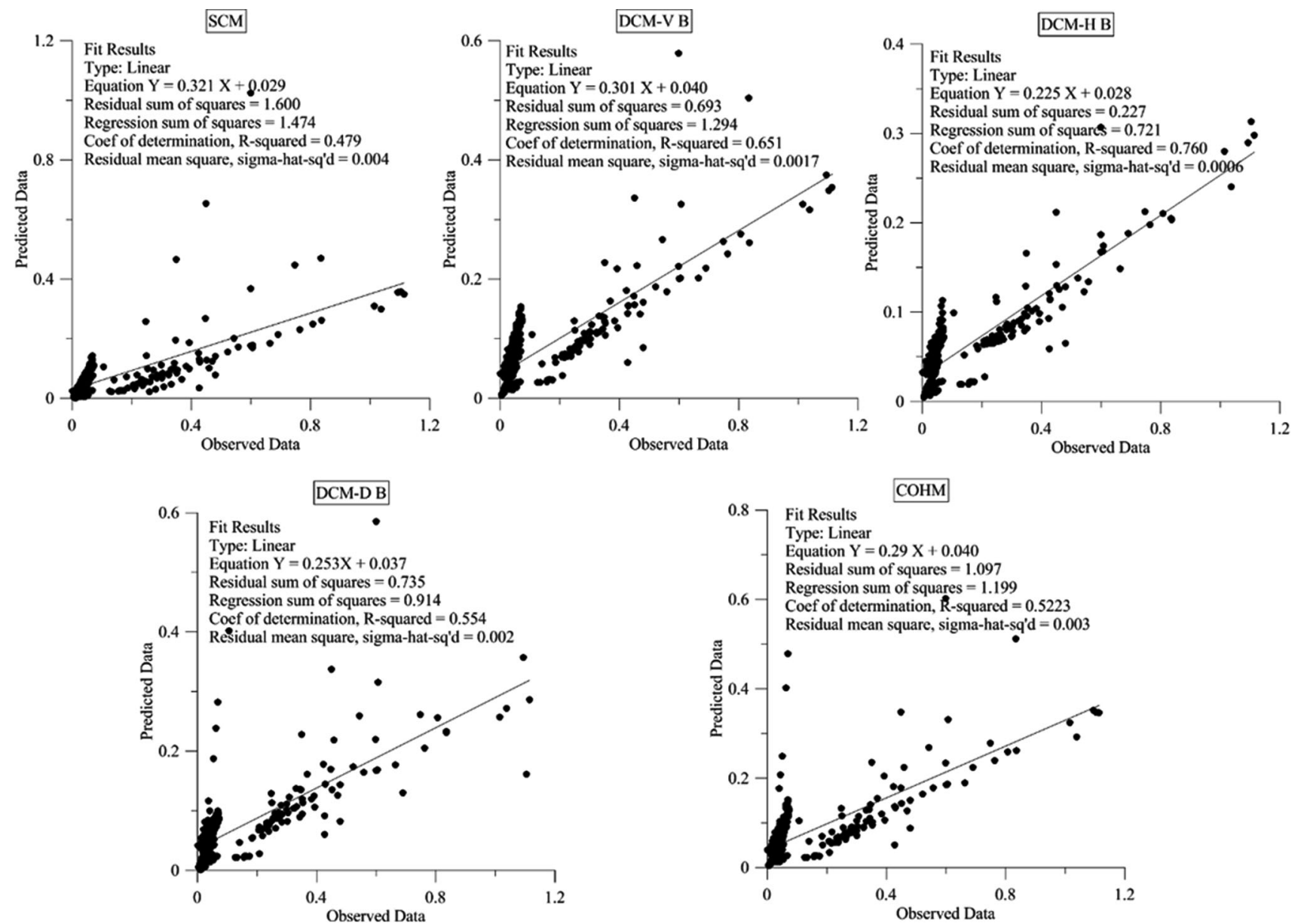

Fig. 5 Results of the analytical approaches for calculating flow discharge 
network consisting of inputs layer, hidden layer (layers) and outputs layer. As shown in Fig. 3. $w_{i}$ is the weight and $b_{i}$ is the bias for each neuron. Weight and biases' values will be assigned progressively and corrected during training process comparing the predicted outputs with known outputs. Such networks are often trained using back propagation algorithm. In the present study, ANN was trained by Levenberg-Marquardt technique because this technique

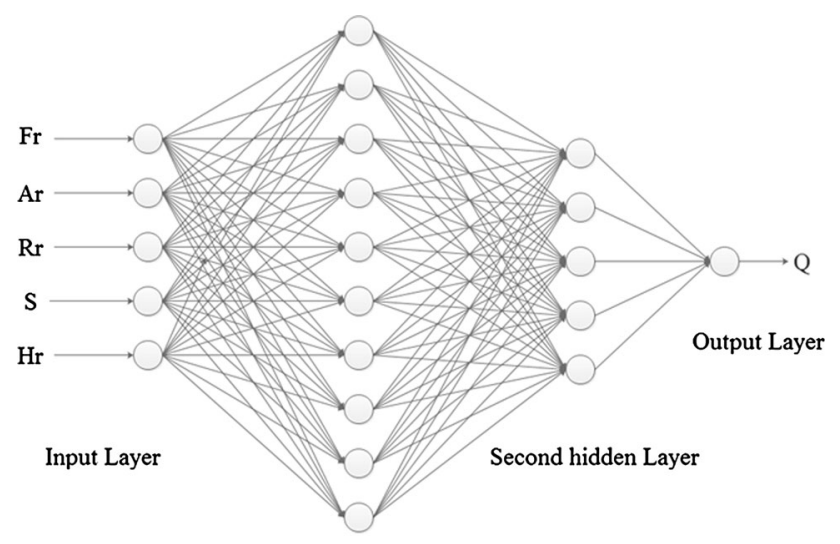

First hidden Layer

Fig. 6 The structure of the MLP model is more powerful and faster than the conventional gradient descent technique (Parsaie and Haghiabi 2015a; Parsaie et al. 2015b; Parsaie and Haghiabi 2015b).

\section{Radial basis function neural network}

Radial Basis Function (RBF) Neural Network is a type of artificial neural networks which widely uses in image processing, pattern recognition and nonlinear system modeling. The RBF model as shown in the Fig. (3) consist of two layers, the first layer considered as hidden layer and second layer as output layer. The radial function is considered as transfer function for the neurons which are in the hidden layer and linear function as output layer transfer function. Designing the RBF neural network is based on the defining the center of these functions in other to the aim of RBF model training is mapping the input space to output space as $f: R^{n} \rightarrow R$. The transfer function of the RBF model is defined as Eq. (5).

$f(v)=\sum_{i=1}^{n} w_{i} \varphi\left(\left\|v-c_{i}\right\|\right)$,

where $v$ is the inputs variable, $w_{i}$ is the weight coefficients, $\varphi$ is Gaussian function which is the basic function that uses
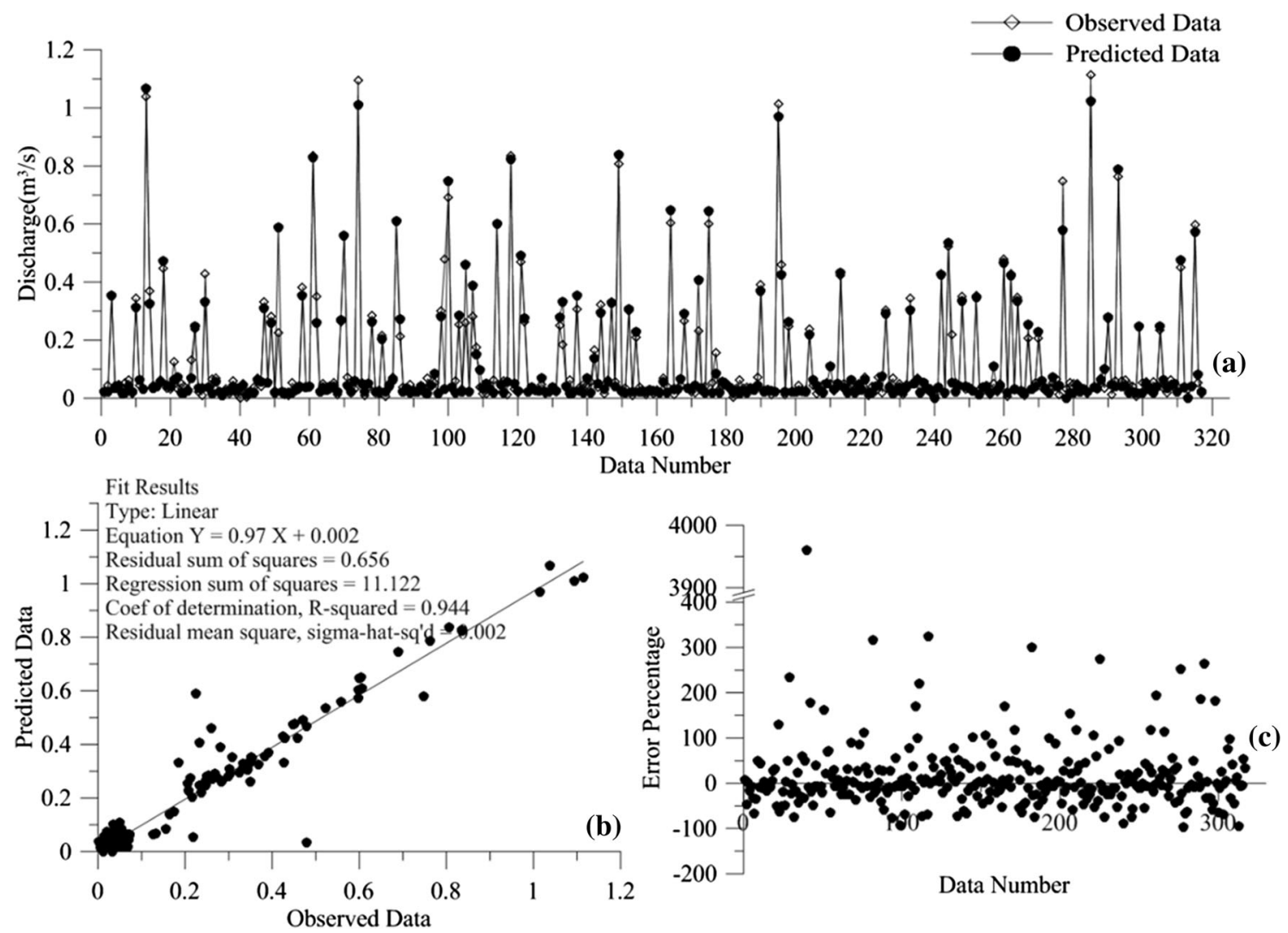

Fig. 7 The performance of MLP model in training stage a results of MLP together with the observed data, $\mathbf{b}$ results of MLP model versus the observed data, $\mathbf{c}$ error percentage 

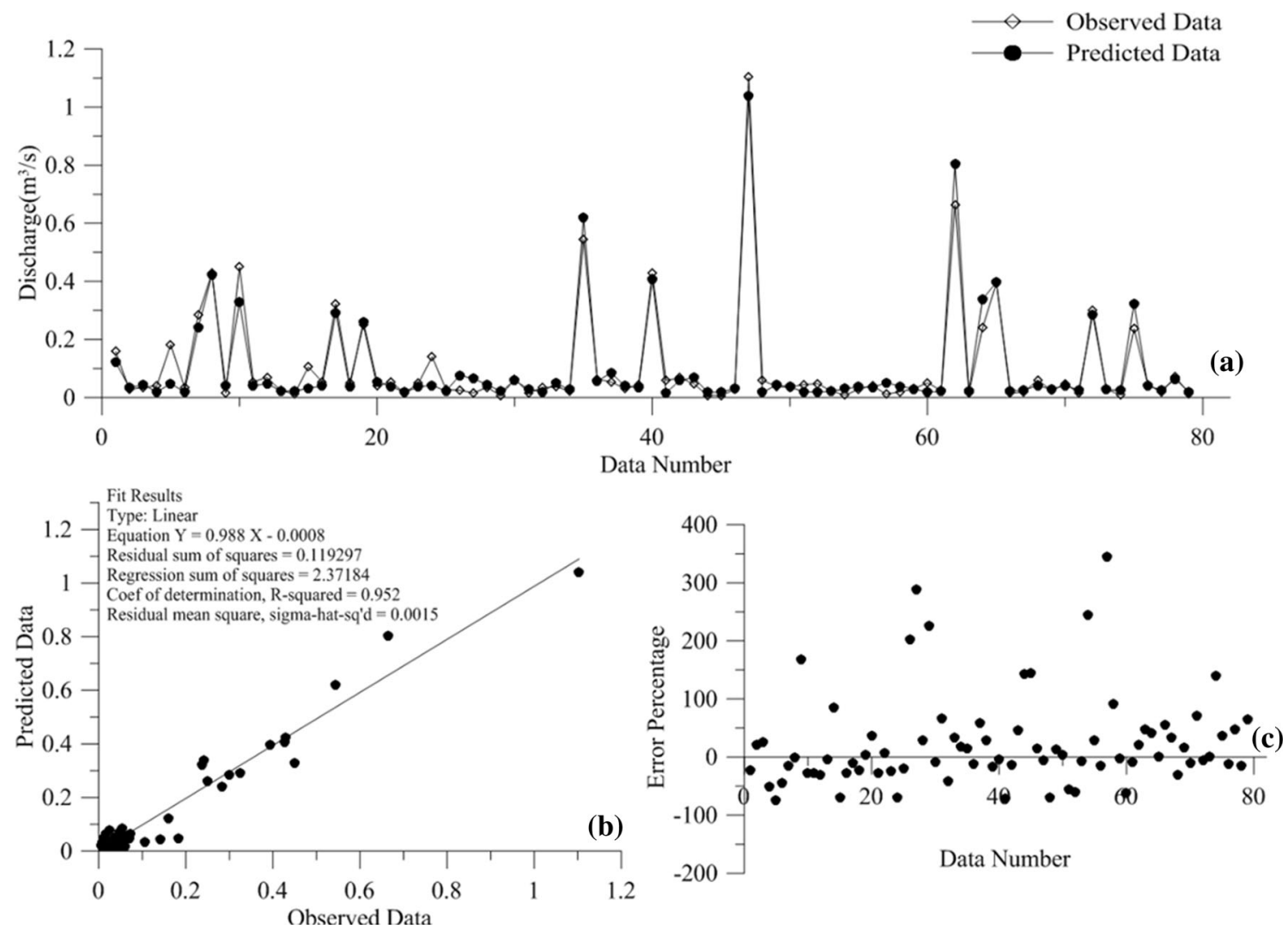

Fig. 8 The performance of MLP model in testing stage a results of MLP together with the observed data, $\mathbf{b}$ results of MLP model versus the observed data, $\mathbf{c}$ error percentage

Fig. 9 The architect of the RBF model

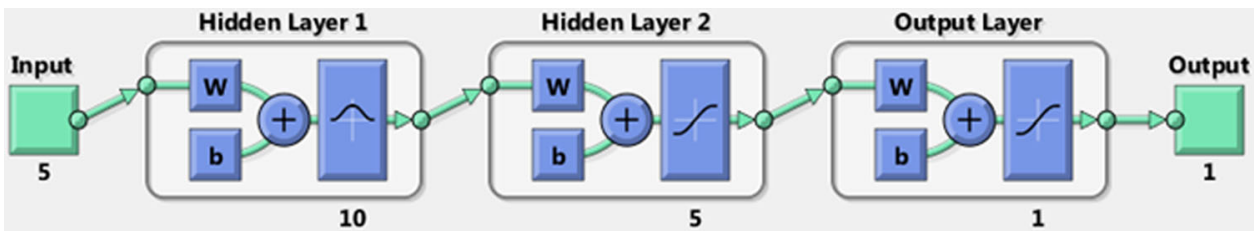

as kernel function in RBF model development and defines as Eq. (6).

$\varphi(v)=e^{\left(\frac{-v^{2}}{2 \sigma^{2}}\right)}$.

The RBF model training usually is carried out by Gradient Descent approach. The aim of the RBF model is defining the value of the kernel function parameters and weights. Initial value of the weights is defined randomly. The error for each sample of the data set is calculated as Eq. (7).

$e_{i}=t_{i}-y_{i}=t_{i}-\sum_{j=}^{N} w_{j} \varphi\left(\left\|v_{i}-c_{i}\right\|\right)$

The error for the total input data set is calculated as Eq. (8).
$E=\frac{1}{2} \sum_{i=1}^{p}\left|e_{i}\right|^{2}$

The RBF model is finished when the error of the RBF model for all the data set is lower than the threshold error which is defined by designer (Parsaie and Haghiabi 2015c) (Fig. 4).

\section{Results and discussion}

The performance of empirical formulas to calculate discharge of flow in compound channel were compare with observed collected dataset. Results of SCM, DCM and COHM are shown in Fig. 5. To quantitative assessment, error indices such as coefficient of determination $\left(\mathrm{R}^{2}\right)$ were 
Fig. 10 The performance of the RBF model during the training stage

Fig. 11 The performance of the RBF model during the testing stage
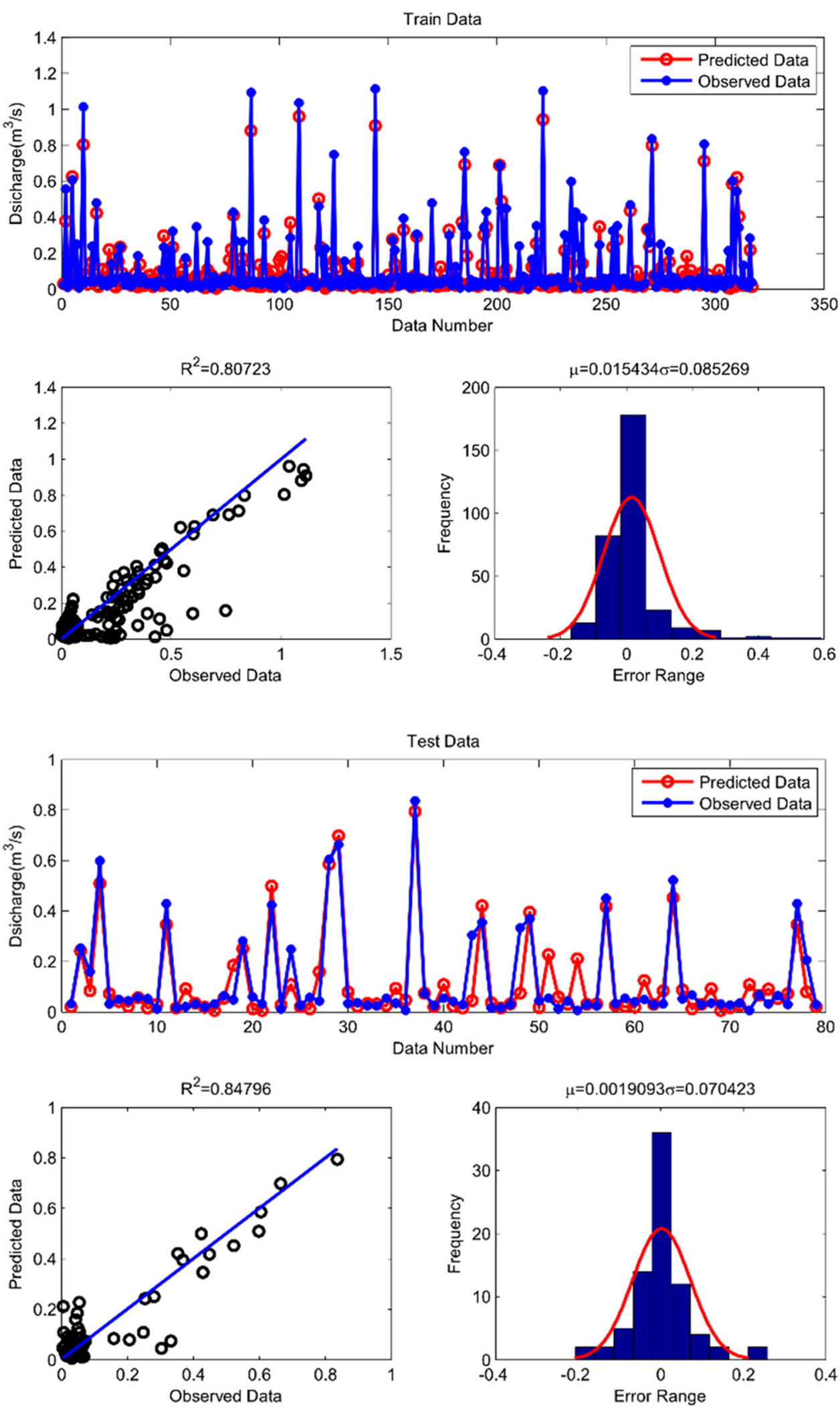
calculated and are shown in Fig. 5. As shown in Fig. 5, the best accuracy is related to the DCM with horizontal separated line with $\left(\mathrm{R}^{2}=0.76\right)$.

\section{ANN models results}

Developing the MLP and RBF models is based on the data set. The data set was divided in two groups as training and testing data. Data selection for the ANN model training and testing process carried out by randomly approach. Designing the ANN model structure is more based on the designer experience but the investigators recommendation who conducted similar research is useful. In this paper, to design the structure of ANN, recommendation by Azamathulla et al. (2016) were considered. Designing the ANN model including number of steps as follow: type of neural network model, number of the hidden layer(s), number of the neurons in each layer, and defining the suitable transfer function for the neurons of hidden and output layers and training algorithm.

\section{MLP models results}

The MLP model contains two layers; inputs and hidden layers. The hidden layer contains ten (10) neurons and transfer functions were tangent sigmoid (tansig). The MLP model structure is shown in Fig. (6). The training of the MLP model was performed with levenberg_marquat technique. $80 \%$ of data set was used for training and remains (20\%) was considered for testing the model. The performance of MLP model in development stages (Train and Testing) are shown in the Figs. (7 and 8) and to assess the performance of this model, error indices for each stage of preparation was calculated and presented in the these Figures. Figures (7 and 8) shows that the accuracy of the MLP model is suitable for prediction of flow discharge. To evaluate the error density the error the error percentage was plotted as well.

\section{RBF models results}

To assess the accuracy of the RBF model for prediction of the $Q_{m}$ and also compering its performance with MLP model tried to hold similar conditions for model development. In other word, tried to hold similar number of the training and testing dataset. In addition, tried to similar hold the number of the neurons in the input layer. The architect of the RBF model is shown in Fig. (9). As show in the Fig. (9) the input layer neurons was considered as equal to the MLP model input later. The performance of the RBF model during the training and testing model are shown in the Figs. (10 and 11). As shown from these figures, the performance of the RBF model is a bit less than the MLP.

\section{Conclusion}

In this study discharge of flow $\left(Q_{m}\right)$ was calculated and predicted by empirical approaches, radial basis function (RBF) neural network and multilayer perceptron (MLP) neural network. The results of this study indicate that the divided channel method with assuming horizontal as virtual separated lines between the subsections is accurate among the empirical approaches. To achieve more accuracy for $Q_{m}$ prediction, the MLP model and RBF model were developed. To prepare the MLP and RBF models the about 396 data set related the $Q_{c m p}$ was collected. The result of the assessing the performance of the MLP shows that the MLP model has suitable performance to predict the $Q_{c m p}$. The results of the RBF model development indicated the accuracy of this model is a little less than the MLP model.

\section{References}

Ackers P (1993) Flow formulae for straight two-stage channels. J Hydraul Res 31:509-531

Al-Khatib IA, Dweik AA, Gogus M (2012) Evaluation of separate channel methods for discharge computation in asymmetric compound channels. Flow Meas Instrum 24:19-25

Al-Khatib I, Hassan H, Abaza K (2013) Application and validation of regression analysis in the prediction of discharge in asymmetric compound channels. J Irrig Drain Eng 139:542-550

Atabay S, Knight DW (2006) 1-D modelling of conveyance, boundary shear and sediment transport in overbank flow. J Hydraul Res 44:739-754

Azamathulla HM, Zahiri A (2012) Flow discharge prediction in compound channels using linear genetic programming. J Hydrol 454-455:203-207

Azamathulla HM, Haghiabi AH, Parsaie A (2016) Prediction of side weir discharge coefficient by support vector machine technique. Water Science and Technology: Water Supply. doi:10.2166/ws. 2016.014

Chow V, Maidment D, Mays L (2013) Applied hydrology, 2nd edn. McGraw-Hill, New York

Dehdar-Behbahani S, Parsaie A (2016) Numerical modeling of flow pattern in dam spillway's guide wall. case study: Balaroud dam, Iran. Alex Eng J 55:467-473

Khatua K, Patra K, Mohanty P (2012) Stage-discharge prediction for straight and smooth compound channels with wide floodplains. J Hydraul Eng 138:93-99

Knight DW, Demetriou JD, Hamed ME (1984) Stage discharge relationships for compound channels. In: Smith KVH (ed) Channels and channel control structures. Springer, Berlin Heidelberg

Kozioł A (2013) Three-dimensional turbulence intensity in a compound channel. J Hydraul Eng 139:852-864

Lenton R, Muller M (2012) Integrated water resources management in practice: better water management for development. Taylor \& Francis, London 
Moasheri SA, Goshki AS, Parsaie A (2013) "SAR" qualities parameter persistence by a compound method of geostatic and artificial neural network (case study of jiroft plain). Int J Agric Crop Sci 6:157-166

Mohanty PK, Khatua KK (2014) Estimation of discharge and its distribution in compound channels. J Hydrodyn Ser B 26:144-154

Naot D, Nezu I, Nakagawa H (1993) Calculation of compound-openchannel flow. J Hydraul Eng 119:1418-1426

Othman F, Valentine EM (2006) Numerical modelling of the velocity distribution in a compound channel. J Hydrol Hydromech 54:269-279

Padhi E, Patra K (2014) Stage discharge prediction in a prismatic compound channel. Int J Civ Eng Res 5:227-232

Parsaie A (2016) Analyzing the distribution of momentum and energy coefficients in compound open channel. Model Earth Syst Environ 2:1-5

Parsaie A, Haghiabi A (2014) Predicting the side weir discharge coefficient using the optimized neural network by genetic algorithm. Sci J Pure Appl Sci 3:103-112

Parsaie A and Haghiabi A (2015a) Computational modeling of pollution transmission in rivers. Appl Water Sci 1-10. doi:10. 1007/s13201-015-0319-6

Parsaie A, Haghiabi A (2015b) The effect of predicting discharge coefficient by neural network on increasing the numerical modeling accuracy of flow over side weir. Water Resour Manage 29:973-985

Parsaie A, Haghiabi AH (2015c) Predicting the longitudinal dispersion coefficient by radial basis function neural network. Model Earth Syst Environ 1:1-8

Parsaie A and Haghiabi AH (2016) Prediction of discharge coefficient of side weir using adaptive neuro-fuzzy inference system. Sustain Water Resour Manage 1-8. doi:10.1007/s40899-0160055-6

Parsaie A, Haghiabi AH, Moradinejad A (2015a) CFD modeling of flow pattern in spillway's approach channel. Sustain Water Resour Manag 1:245-251

Parsaie A, Haghiabi AH, Saneie M, Torabi H (2016) Prediction of energy dissipation on the stepped spillway using the multivariate adaptive regression spline. ISH J Hydraul Eng 22:281-292. doi:10.1080/09715010.2016.120178
Parsaie A, Yonesi H, Najafian S (2015b) Predictive modeling of discharge in compound open channel by support vector machine technique. Model Earth Syst Environ 1:1-6

Qishlaqi A, Kordian S and Parsaie A (2016) Hydrochemical evaluation of river water quality - a case study. Appl Water Sci 1-6. doi:10.1007/s13201-016-0409-0

Rezaei B, Knight DW (2009) Application of the Shiono and Knight Method in compound channels with non-prismatic floodplains. J Hydraul Res 47:716-726

Sahu M, Khatua KK, Mahapatra SS (2011) A neural network approach for prediction of discharge in straight compound open channel flow. Flow Meas Instrum 22:438-446

Seckin G (2004) A comparison of one-dimensional methods for estimating discharge capacity of straight compound channels. Can J Civ Eng 31:619-631

Seckin G, Mamak M, Atabay S, Omran M (2009) Discharge estimation in compound channels with fixed and mobile bed. Sadhana 34:923-945

Tang X, Knight DW, Samuels PG (1999) Variable parameter Muskingum-Cunge method for flood routing in a compound channel. J Hydraul Res 37:591-614

Te Chow V (2009) Open-channel hydraulics. Blackburn, Caldwell

Unal B, Mamak M, Seckin G, Cobaner M (2010) Comparison of an ANN approach with 1-D and 2-D methods for estimating discharge capacity of straight compound channels. Adv Eng Softw 41:120-129

Wang W, Huai WX, Gao M (2014) Numerical investigation of flow through vegetated multi-stage compound channel. J Hydrodyn Ser B 26:467-473

Wormleaton P, Hadjipanos P (1985) Flow distribution in compound channels. J Hydraul Eng 111:357-361

Wormleaton PR, Merrett DJ (1990) An improved method of calculation for steady uniform flow in prismatic main channel/ flood plain sections. J Hydraul Res 28:157-174

Yonesi HA, Omid MH, Ayyoubzadeh SA (2013) The hydraulics of flow in non-prismatic compound channels. J Civ Eng Urban 3:342-356

Zahiri A, Azamathulla HM (2014) Comparison between linear genetic programming and M5 tree models to predict flow discharge in compound channels. Neural Comput Appl 24:413-420 